Article

\title{
Electromechanical Transient Modeling of Line Commutated Converter-Modular Multilevel Converter-Based Hybrid Multi-Terminal High Voltage Direct Current Transmission Systems
}

\author{
Liang Xiao ${ }^{1}(\mathbb{D})$, Yan $\mathrm{Li}^{2}$, Huangqing Xiao ${ }^{1}{ }^{(\mathbb{D})}$, Zheren Zhang ${ }^{1}$ and Zheng $\mathrm{Xu}{ }^{1, *(1)}$ \\ 1 College of Electrical Engineering, Zhejiang University, Hangzhou 310027, China; \\ xlxiaoliang@zju.edu.cn (L.X.); xhqhz@zju.edu.cn (H.X.); zhangzheren@zju.edu.cn (Z.Z.) \\ 2 State Grid Jiangsu Electric Power Co., Ltd., Nanjing 210000, China; liyan.lyg@js.sgcc.com.cn \\ * Correspondence: xuzheng007@zju.edu.cn; Tel.: +86-0571-8795-2074
}

Received: 7 July 2018; Accepted: 9 August 2018; Published: 13 August 2018

check for updates

\begin{abstract}
A method for electromechanical modeling of line commutated converter (LCC)-modular multilevel converter (MMC)-based hybrid multi-terminal High Voltage Direct Current Transmission (HVDC) systems for large-scale power system transient stability study is proposed. Firstly, the general idea of modeling the LCC-MMC hybrid multi-terminal HVDC system is presented, then the AC-side and DC-side models of the LCC/MMC are established. Different from the conventional first-order DC-side model of the MMC, an improved second-order DC-side model of the MMC is established. Besides considering the firing angle limit of the LCC, a sequential power flow algorithm is proposed for the initialization of LCC-MMC hybrid multi-terminal HVDC system. Lastly, simulations of small scale and large scale power systems embedded with a three-terminal LCC-MMC hybrid HVDC system are performed on the electromechanical simulation platform PSS/E. It is demonstrated that if the firing angle limit is not considered, the accuracy of the power flow solutions will be greatly affected. Steady state calculation and dynamic simulation show that the developed LCC-MMC hybrid MTDC model is accurate enough for electromechanical transient stability studies of large-scale AC/DC system.
\end{abstract}

Keywords: electromechanical modeling; hybrid multi-terminal HVDC system; line commutated converter (LCC); modular multilevel converter (MMC); sequential power flow algorithm

\section{Introduction}

According to the differences of switching devices used in converters, multi-terminal HVDC (MTDC) transmission systems can be divided into LCC-based MTDC systems, voltage source converter (VSC) based MTDC systems, and LCC-VSC hybrid MTDC systems [1]. In recent years, the hybrid HVDC systems have drawn more and more attention both from academic and industrial fields because of the combined advantages of LCC and VSC (especially the MMC) [2-14]. Previous studies about hybrid HVDC systems mainly focused on electromagnetic transient modeling [4-7], control protection strategies [8-10] and harmonic analyses [11,12], which are mainly based on the electromagnetic transient simulation platform. However, the electromagnetic transient simulation is not suitable for large-scale AC/DC power system transient stability studies. This is because, with the high penetration of power electronic devices in modern power systems, the large number of switching devices limit the speed and scale of electromagnetic transient simulation [15-17].

Currently, the first LCC-MMC hybrid three-terminal HVDC project (shown in Figure 1) delivering bulk power from Yunnan (YN) to Guangxi (GX) and Guangdong (GD) province is under construction 
by the China Southern Power Grid (CSPG). Before the project can be officially put into operation, complete transient stability evaluations of the CSPG embedded with the hybrid HVDC system need to be performed. However, generic hybrid LCC-MMC MTDC models are currently unavailable in electromechanical transient simulation tools (e.g., Power System Simulation for Engineering, PSS/E). Consequently, the introduction of LCC-MMC hybrid MTDC system brings new challenges on the planning operation and transient stability study of large-scale AC/DC power systems. Under these backgrounds, it is urged to develop a generic LCC-MMC hybrid MTDC electromechanical model in commercial simulation tools.

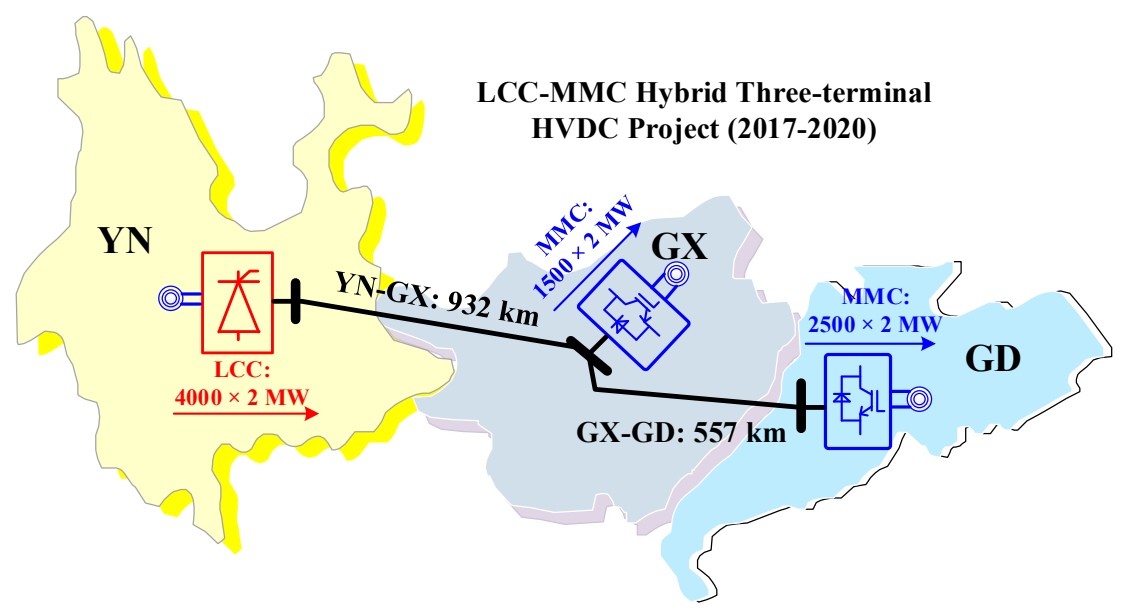

Figure 1. The first multi-terminal LCC-MMC hybrid HVDC project in China.

It is a common practice is to use the electromechanical transient simulation method for transient stability study of large-scale AC/DC power systems [18]. The essence of electromechanical simulation is solving the system differential-algebraic equations (DAEs) numerically to obtain the dynamic responses of the power system. Mathematically, to develop the electromechanical model of the hybrid HVDC system is to establish the corresponding DAEs that describing the system dynamic behaviors. Thus the electromechanical model is the foundation for transient stability study. As a new component of the power systems, modeling of LCC-MMC hybrid MTDC system for transient stability study has only been reported by a few papers. Small-signal models of hybrid LCC-VSC HVDC links were developed in $[13,14]$ to investigate the hybrid AC/DC system oscillation modes and the impact of parameters on system dampings. However, the linearized small-signal model cannot be applied to transient stability analyses where large disturbances are considered. In [19], an electromechanical model of point-to-point LCC-MMC hybrid HVDC link was established for the integration of large-scale offshore windfarms, and the control design approach was also presented. In [20], an electromechanical model of the LCC-MMC hybrid HVDC grid was developed in PSASP (Power System Analysis Software Package, PSASP) to allow users to build cases freely. However, these hybrid HVDC models were oversimplified in terms of the DC-side model of the MMC; besides, the initializations of the AC/DC systems were not addressed.

Performing the initialization of the hybrid HVDC system is the preliminary work for numerical integration based transient simulation. This process is achieved by AC/DC power flow calculations. As for AC/DC power flow solutions, both unified algorithms [21-23] and sequential algorithms [24-27] are theoretically feasible. Specific to AC/DC networks embedded with hybrid HVDC systems, only a few papers addressed their power flow solutions. In [23], the unified approach was adopted to solve the hybrid AC/DC system equations by forming the augmented Jacobian matrix. The major disadvantage of this algorithm is that it cannot make full use of the existing transient simulation tools (e.g., PSS/E) for large-scale power system analyses. In other words, this algorithm is somewhat impractical since users generally do not have the access to modify the Jacobian matrix in commercial 
simulation tools. In [26], a sequential power flow algorithm was developed by considering the control strategy of hybrid HVDC grids as well as the converter transformer turns ratio. However, the firing angle limit of the LCC was not considered. And it will affect the accuracy of the power flow solutions to a significant extent since the reactive power and other electrical quantities of the LCC are interrelated to the firing angle. In a word, a sequential algorithm is preferred for large-scale AC/DC power system initialization and its application to LCC-MMC hybrid MTDC system has not been well investigated.

To tackle these issues, this paper proposes an electromechanical model of LCC-MMC hybrid MTDC system for large-scale power system transient stability study. The contributions are summarized as follows:

(1) An improved electromechanical model of LCC-MMC hybrid MTDC system is proposed. Specifically, the DC-side model of the MMC is established as a second-order model, which is more accurate than the conventional first-order DC-side model of the MMC.

(2) Considering the firing angle limits of LCC, we propose a sequential power flow algorithm for the initialization of the LCC-MMC hybrid MTDC system.

This paper is organized as follows: in Section 2, the general idea for electromechanical modeling of LCC-MMC hybrid MTDC system is presented, and the detailed differential-algebraic equations of LCC-MMC hybrid MTDC system are established. In Section 3, a sequential power flow algorithm is proposed for the initialization of large-scale power systems embedded with hybrid MTDC systems. In Section 4, small-scale and large-scale power system cases are carried out for validating the developed model. Conclusions are drawn in Section 5.

\section{Electromechanical Transient Modeling of LCC-MMC Hybrid Multi-Terminal HVDC System}

A typical LCC-MMC hybrid multi-terminal HVDC transmission system is shown in Figure 1. The LCC-MMC hybrid MTDC system contains at least three converter stations. From the perspective of engineering practice, the LCC station usually serves as a rectifier station to avoid commutation failure, while the MMC station can serve as a rectifier or an inverter because of its flexibility in power control. In order to ensure the stable operation of the hybrid HVDC system, the DC voltage should be properly controlled first of all. In this context, the control strategy of the hybrid HVDC system is determined as one MMC station is responsible for DC voltage control, and all the other LCC /MMC stations are responsible for power controls.

\subsection{General Idea of Modeling}

The overall structure of the hybrid HVDC system is shown in Figure 2. As can be seen from the structure, the modeling tasks mainly include three parts:

- Establishing the AC-side and DC-side models of the LCC/MMC;

- Establishing the controller models of the LCC/MMC;

- Establishing the DC network with arbitrary topology. 


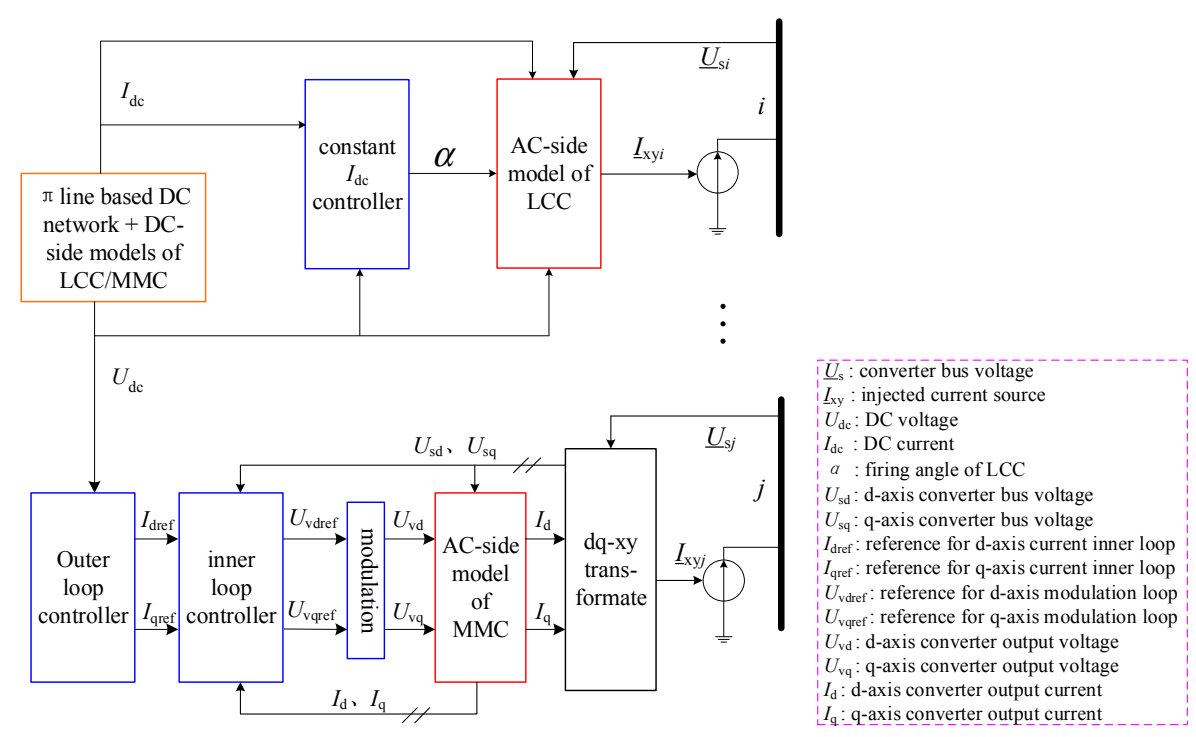

Figure 2. The whole structure of the electromechanical model of the LCC-MMC MTDC system.

During the modeling process, another important issue is to handle the interface between the $\mathrm{LCC} / \mathrm{MMC}$ station and the AC system. It is known that in electro-mechanical simulation tools, the source elements, e.g., generators are all represented as injected current sources [18]. Obviously, the LCC and MMC stations can also be attributed to the category of sources, which need to be converted into the injected current sources. What is more, the electrical quantities of the AC network are represented by the fundamental-frequency phasors in the common network frame (xy-frame), while the MMCs are modeled under the dq synchronous reference frame [28], thus a dq to xy coordinate transformation [29] should be applied to the MMC injected current sources.

\subsection{Modeling of LCC Station}

For bulk power transmissions, it is a common practice to connect six-pulse valve bridges in series to form one pole of an LCC-HVDC link, as shown in Figure 3. The mathematical model of the LCC-based rectifier is given as follows [18].

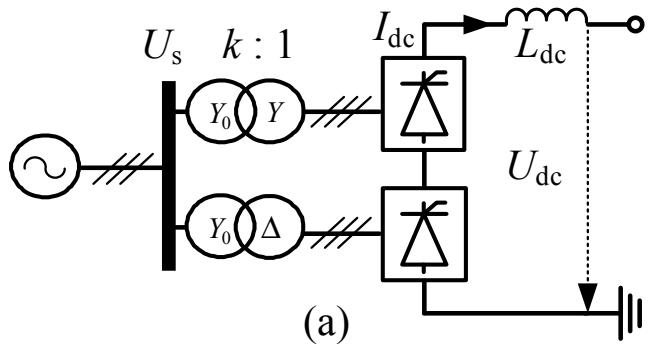

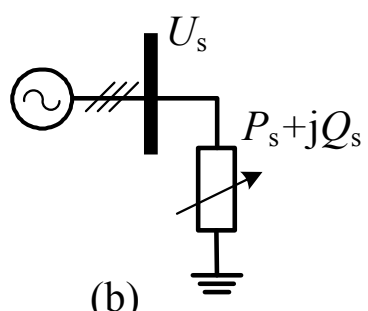

(b)

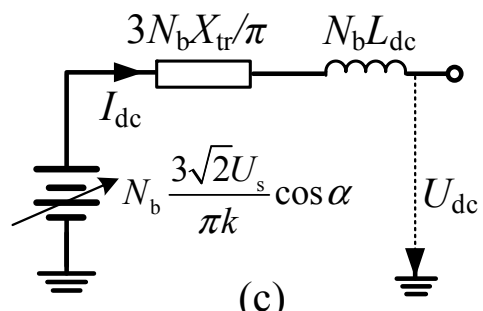

(c)

Figure 3. Schematic circuit of the LCC station. (a) 12-pulse bridge converter; (b) AC-side model of the LCC; (c) DC-side model of the LCC. 


\subsubsection{AC-side Model of the LCC}

From Figure $3 b$, it is shown that the AC-side model of the LCC is expressed as:

$$
\begin{gathered}
P_{\mathrm{s}}=U_{\mathrm{dc}} I_{\mathrm{dc}}, \\
Q_{\mathrm{s}}=\frac{3 N_{\mathrm{b}} U_{\mathrm{s}}^{2}}{4 \pi X_{\mathrm{tr}} k^{2}}[2 \mu+\sin 2 \alpha-\sin (2 \alpha+2 \mu)], \\
\mu=\cos ^{-1}\left[\cos \alpha-\sqrt{2} I_{\mathrm{dc}} X_{\mathrm{tr}} k / U_{\mathrm{s}}\right]-\alpha,
\end{gathered}
$$

where $P_{\mathrm{s}}$ and $Q_{\mathrm{s}}$ denote the active and reactive power of the LCC; $U_{\mathrm{dc}}$ and $I_{\mathrm{dc}}$ denote the DC voltage and DC current; $U_{\mathrm{s}}$ is the RMS line-to-line voltage of the converter bus; $k$ is the transformer ratio, $X_{\mathrm{tr}}$ is the transformer leakage reactance; $N_{\mathrm{b}}$ is the number of six-pulse bridge; $\alpha$ and $\mu$ denote the firing angle and commutation overlap angle, respectively.

From Equations (1)-(3) and Figure 3b, it is clear that the AC-side model of the LCC is characterized by a set of algebraic equations. The AC-side model needs to be converted into the injected current source:

$$
\begin{aligned}
& I_{\mathrm{x}}=\left(P_{\mathrm{s}} U_{\mathrm{sx}}+Q_{\mathrm{s}} U_{\mathrm{sy}}\right) /\left(\sqrt{3} U_{\mathrm{s}}^{2}\right), \\
& I_{\mathrm{y}}=\left(P_{\mathrm{s}} U_{\mathrm{sy}}-Q_{\mathrm{s}} U_{\mathrm{sx}}\right) /\left(\sqrt{3} U_{\mathrm{s}}^{2}\right),
\end{aligned}
$$

where $U_{\mathrm{sx}}$ and $U_{\mathrm{sy}}$ denote the real and imaginary component of the converter bus voltage under the common network frame (xy-frame); $I_{\mathrm{x}}$ and $I_{\mathrm{y}}$ denote the real and imaginary component of the injected current under the xy-frame.

\subsubsection{DC-side Model of the LCC}

From Figure 3c, it is shown that the DC-side model of the LCC is expressed as:

$$
N_{\mathrm{b}} L_{\mathrm{dc}} \frac{\mathrm{d} I_{\mathrm{dc}}}{\mathrm{d} t}=N_{\mathrm{b}} \frac{3 \sqrt{2} U_{\mathrm{s}}}{\pi k} \cos \alpha-N_{\mathrm{b}} \frac{3 X_{\mathrm{tr}}}{\pi} I_{\mathrm{dc}}-U_{\mathrm{dc}},
$$

where $L_{\mathrm{dc}}$ is the inductance of the smoothing reactor. From Equation (6), it is clear that the DC-side model of the LCC is characterized by a first-order differential equation.

\subsubsection{Controller Modeling of the LCC}

The constant direct current controller of the LCC is shown in Figure 4.

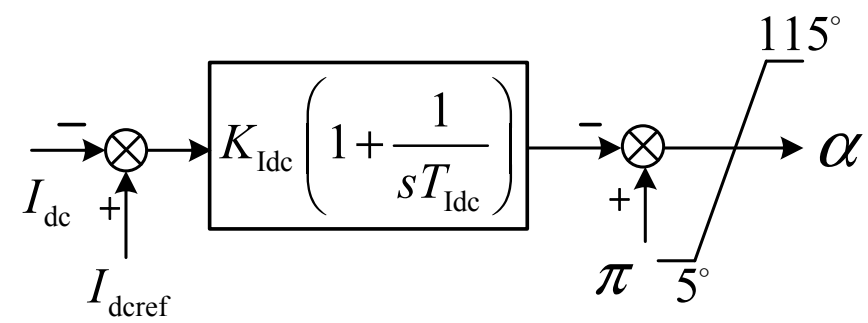

Figure 4. Constant direct current controller of LCC. 
The controller can be described by the following differential-algebraic equations:

$$
\left.\begin{array}{l}
I_{\mathrm{dcref}}=\frac{P_{\mathrm{dcref}}}{U_{\mathrm{dc}}} \\
\alpha=\pi-K_{\mathrm{Idc}}\left(I_{\mathrm{dcref}}-I_{\mathrm{dc}}\right)-M_{\mathrm{Idc}} \\
\frac{\mathrm{d} M_{\mathrm{Idc}}}{\mathrm{d} t}=\frac{K_{\mathrm{Idc}}}{T_{\mathrm{Idc}}}\left(I_{\mathrm{dcref}}-I_{\mathrm{dc}}\right)
\end{array}\right\},
$$

where $P_{\mathrm{dcref}}$ is the DC power reference of the LCC, $I_{\mathrm{dcref}}$ is the DC current reference, $K_{\mathrm{Idc}}$ and $T_{\mathrm{Idc}}$ are the proportional gain and time constant, respectively. $M_{\mathrm{Idc}}$ is the state variable of the controller.

\subsection{Modeling of MMC Station}

There have been lots of researches on the electromechanical modeling of the MMC [19,20,28-31], in which the AC-side modeling and controller modeling have been well studied. Thus the AC-side model of the MMC, the outer loop controller, the inner loop controller and the modulation loop shown in Figure 2 will not be covered for the sake of conciseness. For detailed descriptions of these blocks, please refer to [29]. This section will focus on the improved DC-side model of the MMC.

In the field of electromechanical modeling of the MMC, the DC-side model of the MMC is described by a first-order differential equation without exception $[19,20,28-31]$, where only the dynamic characteristic of the equivalent capacitor is taken into account, as shown in Figure 5a. However, it is reported that the DC-side impedance of the MMC consists of RLC components [11,32], which means that the dynamic characteristic of the arm inductance on the DC side should also be considered. This is understandable since the DC current flows through the arm inductor and arm resistor of the MMC. Consequently, the second-order DC-side model of the MMC should be used, as shown in Figure 5b:

$$
\left.\begin{array}{l}
\frac{2}{3} L_{\mathrm{arm}} \frac{\mathrm{d}}{\mathrm{d} t} I_{\mathrm{dc}}=U_{\mathrm{dc}}-U_{\mathrm{Ceq}}-\frac{2}{3} R_{\mathrm{arm}} I_{\mathrm{dc}} \\
C_{\mathrm{eq}} \frac{\mathrm{d}}{\mathrm{d} t} U_{\mathrm{Ceq}}=I_{\mathrm{dc}}-I_{\mathrm{dcs}}
\end{array}\right\}
$$

where $L_{\mathrm{arm}}$ and $R_{\mathrm{arm}}$ are the arm inductance and arm resistance of the MMC, $C_{\mathrm{eq}}=6 \mathrm{C}_{\mathrm{sm}} / \mathrm{N}$ is the equivalent capacitance of the MMC ( $N$ is the number of sub module per arm, $C_{\mathrm{sm}}$ is the capacitance of sub module), $U_{\text {Ceq }}$ is equivalent capacitor voltage and $I_{\mathrm{dcs}}$ is the controllable DC current source.

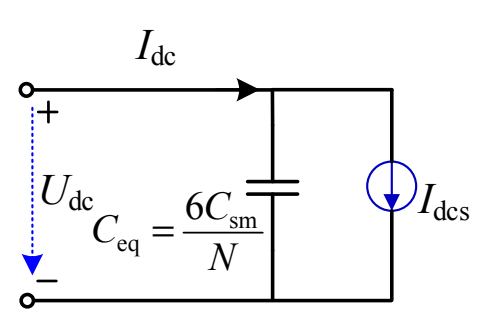

(a)

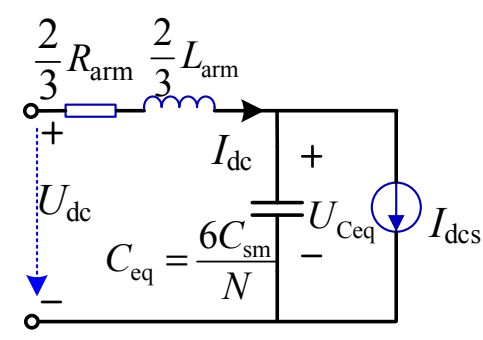

(b)

Figure 5. DC-side model of the MMC. (a) Conventional first-order model; (b) Improved second-order model.

The proposal that the DC-side model of the MMC should be established as a second-order circuit will be verified by the detailed MMC electromagnetic model established in PSCAD (Power Systems Computer Aided Design, PSCAD). The detailed parameters of the MMC-HVDC link are shown in Table A1 given in Appendix A. At $t=1.5 \mathrm{~s}$, a line-to-ground fault occurred at the midpoint of the DC line. The responses of direct currents are shown in Figure 6. From the results, it can be seen that the direct current response of the second-order DC-side model is very much consistent with that of the electromagnetic model. However, the direct current response of the conventional first-order DC-side model is much faster due to the lack of equivalent arm inductance on the DC side. Obviously, the second-order DC-side model of the MMC is more accurate than the conventional one. 


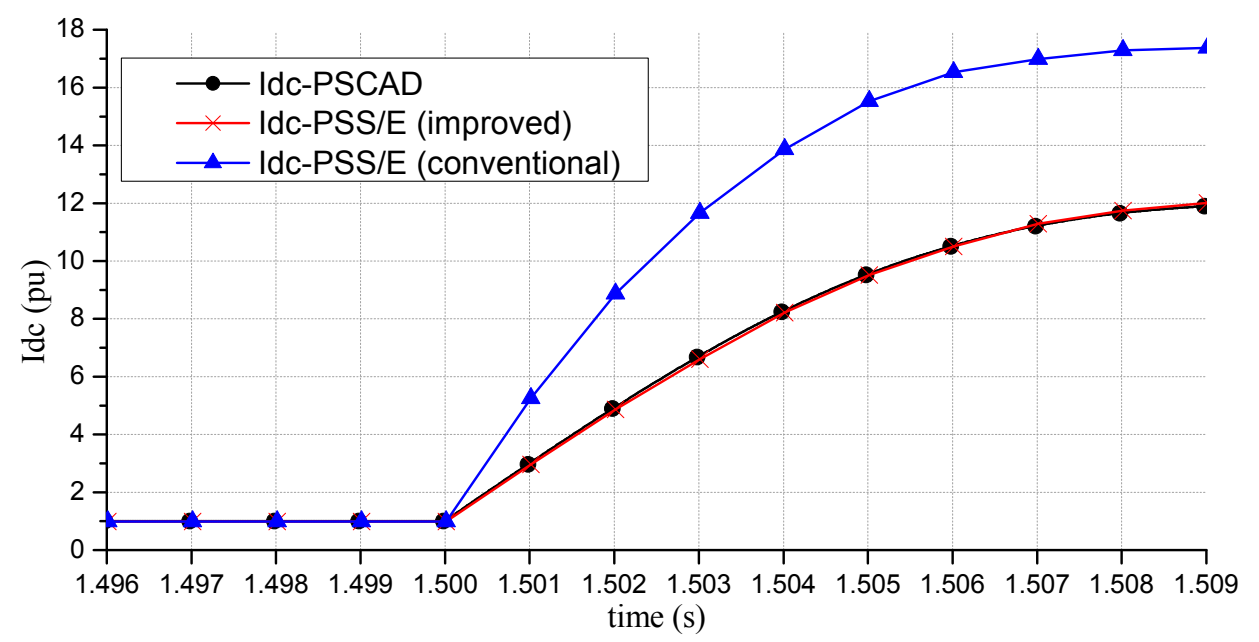

Figure 6. Comparisons of the improved/conventional MMC electromechanical model with the detailed electromagnetic model.

\subsection{Modeling of the Hybrid MTDC Network}

The hybrid MTDC network is shown in Figure 7. It consists of DC-side model of the LCC, second-order DC-side model of the MMC and a $\pi$-line based DC network with arbitrary topology.

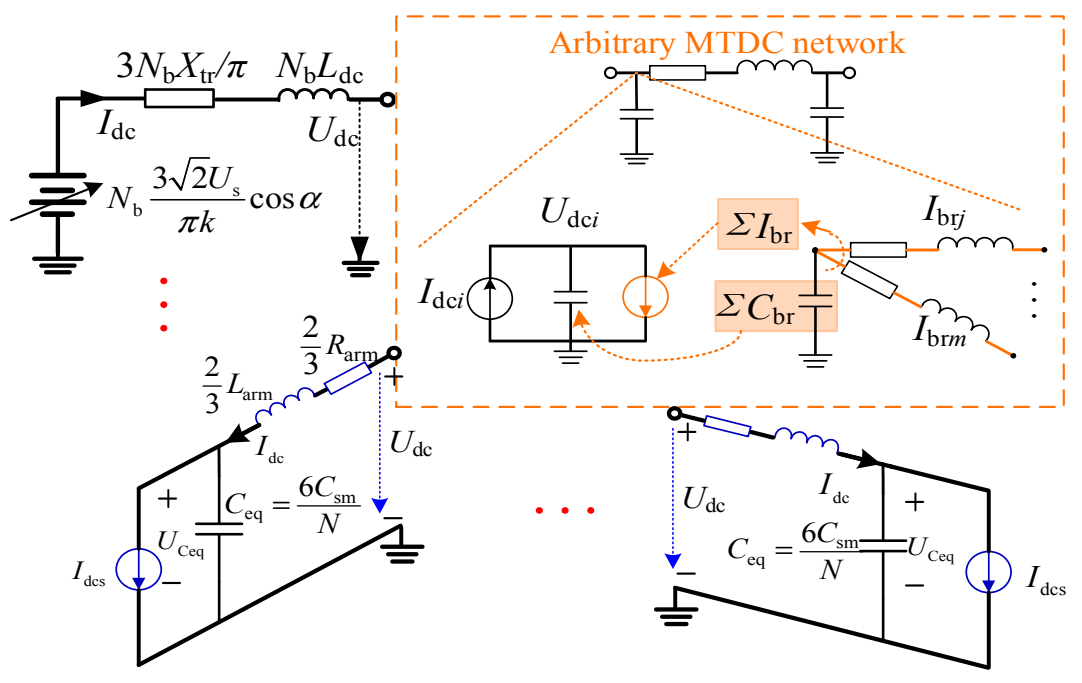

Figure 7. Electromechanical modeling of the hybrid MTDC network.

Specifically, a DC network with arbitrary topology means that there can be joint (intermediate) nodes in the DC network. The corresponding differential equations are written as follows:

1. For the $i$-th DC node:

$$
\sum_{k \in i} C_{\mathrm{brk}} \frac{\mathrm{d} U_{\mathrm{dc} i}}{\mathrm{~d} t}=I_{\mathrm{dc} i}-\sum_{k \in i} I_{\mathrm{brk}}
$$

where $C_{\mathrm{brk}}$ and $I_{\mathrm{brk}}$ are the capacitance and current of the $k$ th DC branch associated with node $i$; $U_{\mathrm{dc} i}$ is the DC voltage of the $i$-th node; if node $i$ belongs to a converter node, $I_{\mathrm{dc} i}$ is the DC current source fed from LCC/MMC station, otherwise $I_{\mathrm{dc} i}$ is zero for the $i$-th intermediate node in a DC network. 
2. For the $k$-th DC branch between node $i$ and node $v$ :

$$
L_{\mathrm{brk}} \frac{\mathrm{d} I_{\mathrm{brk}}}{\mathrm{d} t}=U_{\mathrm{dci}}-U_{\mathrm{dc} v}-R_{\mathrm{brk}} I_{\mathrm{brk}}
$$

where $R_{\mathrm{brk}}$ and $L_{\mathrm{brk}}$ are the resistance and inductance of the $k$ th DC branch, respectively; $U_{\mathrm{dcv}}$ is the DC voltage of the $v$-th node.

\subsection{Summary of the Differential Algebraic Equations of the LCC-MMC Hybrid MTDC System}

So far, the electromechanical transient modeling of the LCC-MMC hybrid MTDC system has been completed. The corresponding differential-algebraic equations are summarized in Table 1.

Table 1. Differential-algebraic equations of LCC-MMC hybrid MTDC system.

\begin{tabular}{cc}
\hline Components & Differential-Algebraic Equations \\
\hline \multirow{2}{*}{ LCC } & AC-side model: Equation (4) + Equation (5) \\
& DC-side model: Equation (6) \\
& controller model: Equation (7) \\
\hline \multirow{2}{*}{ MMC } & AC-side model: reference [29] \\
& DC-side model: Equation (8) \\
& controller model: reference [29] \\
\hline DC network & Equation (9) + Equation (10) \\
\hline
\end{tabular}

\section{Initialization of the LCC-MMC Hybrid MTDC Systems}

As stated in Section 1, in order to initialize all the state variables of the electromechanical transient model, the power flow calculation needs to be executed before the dynamic simulation. In this section, a sequential power flow algorithm is proposed for the initialization of the large-scale power system embedded with the LCC-MMC hybrid MTDC system. Different from the method presented in [26], the method proposed in this paper considers the LCC firing angle limits, thus ensures the reliability of the calculation results.

\subsection{Determination of Converter Bus Types}

Similar to the power flow solution of pure AC systems, the converter bus should be classified as a PQ, PV bus, etc. According to the general control modes of LCC/MMC stations, converter bus types are determined easily, as summarized in Table 2.

Table 2. Converter Bus Type.

\begin{tabular}{ccc}
\hline Converter & Control Mode & Bus Type \\
\hline LCC & constant $I_{\mathrm{dc}}$ & $\mathrm{PQ}$ \\
\hline & $d$ axis: constant $U_{\mathrm{dc}}+q$ axis: constant $Q_{\mathrm{s}}$ & $\mathrm{PQ}$ \\
\multirow{2}{*}{ MMC } & $d$ axis: constant $U_{\mathrm{dc}}+q$ axis: constant $U_{\mathrm{s}}$ & $\mathrm{PV}$ \\
& $d$ axis: constant $P_{\mathrm{s}}+q$ axis: constant $Q_{\mathrm{s}}$ & $\mathrm{PQ}$ \\
& $d$ axis: constant $P_{\mathrm{s}}+q$ axis: constant $U_{\mathrm{s}}$ & $\mathrm{PV}$ \\
\hline
\end{tabular}

\subsection{Implementation of the Sequential Power Flow Algorithm}

The proposed step-by-step sequential power flow algorithm is illustrated in Figure 8. It mainly includes three parts:

- Solving the AC network with focus on AC/DC interfaces.

- Solving the DC network solution. 
- Solving the internal variables such as firing angles and overlap angles of the LCCs.

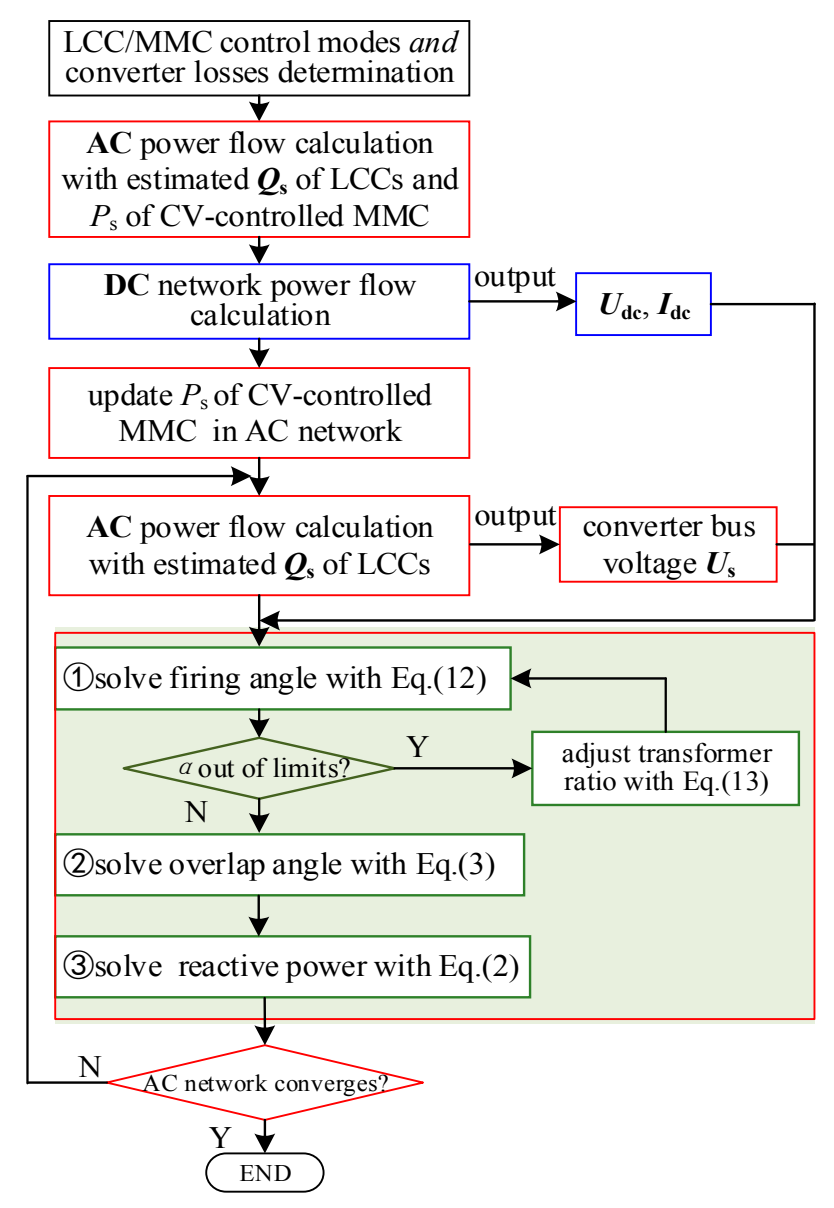

Figure 8. Flow chart of the proposed sequential power flow algorithm.

The solution of the AC network is realized by mature simulation tools (e.g., PSS/E), thus emphases are only placed on the crucial steps given as follows:

1. Solution of the DC network:

The steady state equations of a DC grid are given as:

$$
\left.\begin{array}{l}
P_{\mathrm{dc}}=P_{\text {sref }}-P_{\text {loss }} \\
P_{\mathrm{dc}}=U_{\mathrm{dc}} \otimes\left[Y_{\mathrm{dc}} U_{\mathrm{dc}}\right]
\end{array}\right\},
$$

where $\boldsymbol{P}_{\text {sref }}=\left[P_{\text {sref1 }}, \ldots, P_{\text {sref } n}\right]^{\mathrm{T}}$ is the active power reference of the $n$ total stations, all the elements in $\boldsymbol{P}_{\text {sref }}$ are known except for the constant DC voltage controlled (CV-controlled) station; $P_{\text {loss }}=\left[P_{\text {loss } 1}, \ldots, P_{\text {loss } n}\right]^{\mathrm{T}}=r \% S_{\mathrm{N}}$ is the known converter loss accounts for $r \%$ of the nominal capacity $S_{\mathrm{N}}$; considering that the loss of the LCC station is negligible, only the losses of MMC stations are considered (about $1 \%$ of $S_{\mathrm{N}}$ ) [28]; $\boldsymbol{P}_{\mathrm{dc}}=\left[P_{\mathrm{dc} 1}, \ldots, P_{\mathrm{dc} n}\right]^{\mathrm{T}}$ is the DC power injected to the DC network; $U_{\mathrm{dc}}=\left[U_{\mathrm{dc} 1}, \ldots, U_{\mathrm{dcn}}\right]^{\mathrm{T}}$ is the DC voltage, all the elements in $U_{\mathrm{dc}}$ are unknown except for the $\mathrm{CV}$-controlled station; $\boldsymbol{Y}_{\mathrm{dc}}$ is the DC admittance matrix. Symbol $\otimes$ denotes the element-by-element multiplication.

Obviously, there are $n$ unknown variables ( $n-1$ DC voltages plus one DC power) in $n$ equations of Equation (11), the DC power flow solutions can be obtained easily with the Newton-Raphson 
method [29]. After DC network solutions, the active power of CV-controlled station should be updated in the AC network.

2. Solution of LCC internal variables:

During the AC network solution, we should focus on the interfaces of AC/DC networks as well as the internal variables of converters. For LCC stations, the firing angle $\alpha$, overlap angle $\mu$, transformer ratio $k$ and reactive power $Q_{s}$ are unknown and should be solved iteratively. The calculation formula of $\alpha$ can be derived based on the steady-state form of Equation (6):

$$
\alpha=\cos ^{-1}\left[\left(U_{\mathrm{dc}} / N_{\mathrm{b}}+3 X_{\mathrm{tr}} I_{\mathrm{dc}} / \pi\right) \pi k / 3 \sqrt{2} U_{\mathrm{s}}\right]
$$

In normal operation, the typical value of $\alpha$ is in the range of $15^{\circ}$ to $20^{\circ}$ [18]. If $\alpha$ is out of limits during iterations, the transformer ratio $k$ should be adjusted accordingly:

$$
\left.\begin{array}{l}
k=k\left(1-T_{\text {tap }}\right), \alpha<\alpha_{\min } \\
k=k\left(1+T_{\text {tap }}\right), \alpha>\alpha_{\max }
\end{array}\right\}
$$

where $T_{\text {tap }}$ is the step size of the converter transformer tap.

Once the calculated $\alpha$ falls within the ranges, overlap angle $\mu$ can be solved with Equation (3). Subsequently, reactive power $Q_{s}$ can be solved with Equation (2).

In this method, the stand-alone routine for DC power flow solution needs only one execution. AC network solution is performed by mature simulation tools (e.g., PSS/E). Thus, this sequential algorithm can be easily implemented and is particularly suitable for large-scale AC/DC systems.

\section{Case Study}

Two cases are carried out on electromechanical transient simulation platform PSS/E for studying the dynamic performances of the LCC-MMC hybrid MTDC system. In case 1, a hybrid three-terminal HVDC system is connected to the aggregated AC systems, whose topology is the same as the one shown in Figure 1. In case 2, the aforementioned hybrid three-terminal HVDC model is applied to the planned 2019 China Southern Power Grid (CSPG) for dynamic analysis of large-scale AC/DC system.

\subsection{Case 1: Validation of the Electromechanical Model of the LCC-MMC Hybrid MTDC System}

In order to validate the developed electromechanical model of the LCC-MMC hybrid MTDC system, a detailed electromagnetic model of the LCC-MMC hybrid MTDC system is also established in PSCAD. The system parameters of the hybrid MTDC system are shown in Table A2 given in Appendix A.

Before the dynamic simulation, the power flow solution needs to be executed first. By applying the proposed sequential power flow algorithm, it is shown that the PSS/E results considering the firing angle limits given in Table 3 are closed to those steady state values obtained in PSCAD. From the table, it is clearly shown that the maximum error is smaller than $1 \%$, which proves the accuracy of the power flow solution. 
Table 3. Power Flow Results of Case 1.

\begin{tabular}{|c|c|c|c|c|c|}
\hline Item & & LCC-YN & MMC-GX & MMC-GD & Max Error \\
\hline \multirow{6}{*}{ PSCAD } & $P_{\mathrm{s}}(\mathrm{MW})$ & 4012.7 & -1499.8 & -2328.6 & / \\
\hline & $Q_{\mathrm{s}}$ (Mvar) & 2280.3 & 0.0 & 0.0 & / \\
\hline & $U_{\mathrm{s}}(\mathrm{kV})$ & 518.3 & 528.3 & 528.2 & / \\
\hline & $\alpha\left(^{\circ}\right)$ & 15.4 & / & / & / \\
\hline & $U_{\mathrm{dc}}(\mathrm{kV})$ & 828.7 & 810.6 & 800.0 & / \\
\hline & $I_{\mathrm{dc}}(\mathrm{kA})$ & 4.83 & 1.88 & 2.94 & I \\
\hline \multirow{6}{*}{$\begin{array}{c}\mathrm{PSS} / \mathrm{E} \\
\text { (considering firing angle limits) }\end{array}$} & $P_{\mathrm{S}}(\mathrm{MW})$ & 4000.0 & -1500.0 & -2342.5 & $-0.6 \%$ \\
\hline & $Q_{\mathrm{s}}$ (Mvar) & 2258.8 & 0.0 & 0.0 & $0.9 \%$ \\
\hline & $U_{\mathrm{s}}(\mathrm{kV})$ & 517.0 & 527.6 & 527.6 & $0.3 \%$ \\
\hline & $\alpha\left(^{\circ}\right)$ & 15.3 & / & / & $0.6 \%$ \\
\hline & $U_{\mathrm{dc}}(\mathrm{kV})$ & 828.8 & 810.7 & 800.0 & $-0.01 \%$ \\
\hline & $I_{\mathrm{dc}}(\mathrm{kA})$ & 4.83 & 1.87 & 2.96 & $-0.7 \%$ \\
\hline \multirow{6}{*}{$\begin{array}{c}\text { PSS/E } \\
\text { (without considering firing angle limits) }\end{array}$} & $P_{\mathrm{s}}(\mathrm{MW})$ & 4000.0 & -1500.0 & -2342.5 & $-0.6 \%$ \\
\hline & $Q_{\mathrm{s}}$ (Mvar) & 2209.6 & 0.0 & 0.0 & $3.1 \%$ \\
\hline & $U_{\mathrm{s}}(\mathrm{kV})$ & 516.5 & 527.6 & 527.6 & $0.3 \%$ \\
\hline & $\alpha\left(^{\circ}\right)$ & 14.2 & / & / & $7.8 \%$ \\
\hline & $U_{\mathrm{dc}}(\mathrm{kV})$ & 828.8 & 810.7 & 800.0 & $-0.01 \%$ \\
\hline & $I_{\mathrm{dc}}(\mathrm{kA})$ & 4.83 & 1.87 & 2.96 & $-0.7 \%$ \\
\hline
\end{tabular}

However, if the firing angle limits are not taken into considering, the accuracy of the power flow solutions will be greatly affected as shown in Table 3. Under this circumstance, significant errors occur in the electrical quantities of the LCC (e.g., the error of the firing angle $\alpha$ is up to $7.8 \%$, and the error of the reactive power is up to $3.1 \%$ ). As a result, when solving the power flows of the hybrid AC/DC systems, the firing angle limits should be considered.

After the power flow is obtained, all state variables of the hybrid MTDC electromechanical model can be initialized for subsequent dynamic simulation. A step change of the LCC's DC power reference from $4000 \mathrm{MW}$ to $3800 \mathrm{MW}$ at $t=3.0 \mathrm{~s}$ is performed both in PSS/E and PSCAD for validating the developed electromechanical model. The dynamic responses are shown in Figure 9.

From Figure 9, it can be observed that when the active power transferred from the $\mathrm{YN}$ region is reduced, the firing angle $\alpha$ is regulated from $15.3^{\circ}$ to about $17.3^{\circ}$, as shown in Figure $9 \mathrm{~b}$. This is because the $I_{\mathrm{dc}}$ reference of the LCC controller is reduced with the reduction of the transferred active power. With the help of the constant current controller, the firing angle $\alpha$ must increase in order to regulate the actual $I_{\mathrm{dc}}$ to the target value. In this case, the sending-end YN LCC station serves as a rectifier, while the receiving-end GD and GX MMC stations operate as inverters. At the instant of the power reduction, the power drawn from the $\mathrm{YN}$ is less than those injected into the GX and $\mathrm{GD}$, thus leads to a DC voltage sag during the transient, as shown in Figure 9c. With the help of the constant $U_{\mathrm{dc}}$ controller of the GD MMC station, the DC voltage is pulled back to $800 \mathrm{kV}$ quickly. From Figure 9, it can be seen that the dynamic responses of the hybrid MTDC electromechanical model are very much consistent with those of the electromagnetic model, thus the accuracy of the developed electromechanical model is validated. 


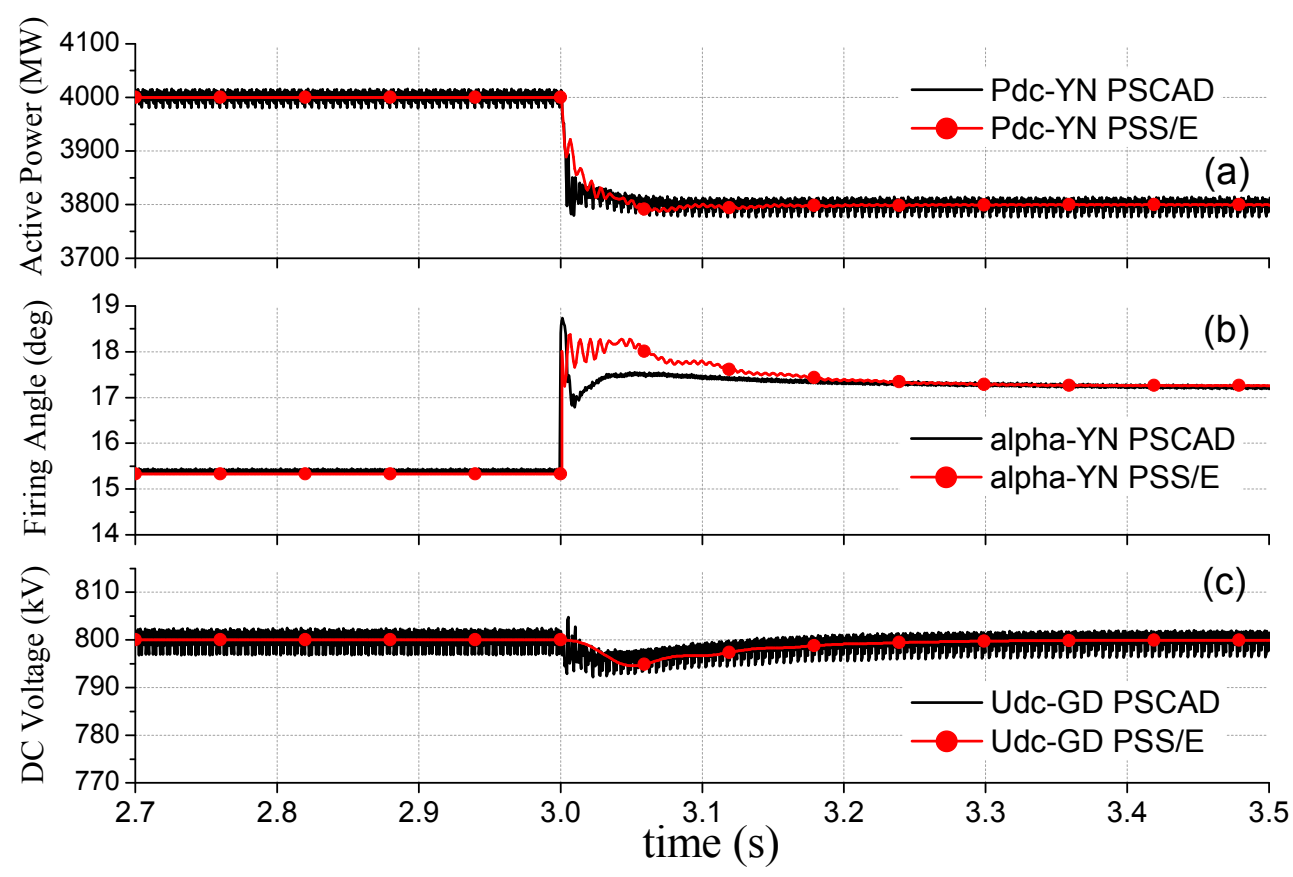

Figure 9. System responses of the electromechanical model compared with the electromagnetic model.

(a) Active power of the LCC; (b) Firing angle of the LCC; (c) DC voltage of the GD MMC.

\subsection{Case 2: Dynamic Analysis of the Large-Scale AC/DC System Embedded with a Hybrid MTDC System}

The planned 2019 CSPG embedded with the hybrid three-terminal HVDC system, is built on PSS/E with about $168 \mathrm{GW}$ installed capacity and 13498 buses for transient stability studies. During the simulations, the GD MMC station is responsible for DC voltage control; the YN LCC and the GX MMC stations are in constant power transmission mode. Other parameters of the hybrid MTDC system are the same as those in case 1, as shown in Table A2.

1. AC fault at the receiving-end GX MMC station:

In this case, a three-phase short circuit fault with $0.1 \mathrm{~s}$ duration is applied at the bus of the receiving-end GX MMC station, leading the bus voltage drops to 0.65 pu during the fault. The dynamic responses are shown in Figure 10.

It is observed that during the fault at the GX converter bus, the power injected to the GX decreases, and the power imbalance is mainly compensated by the DV-controlled GD MMC station, as shown in Figure 10c. However, due to the limited spare capacity of the GD MMC station, the power injected to the GD MMC station reaches the maximum value soon, thus the power drawn from the sending-end YN region is more than those injected into the receiving-end GX and GD regions, leading a DC voltage surge during the transient, as shown in Figure 10d.

From Figures 4 and 7, it is noted that the increase of the DC voltage will lead to a decrease of the current reference of the LCC constant current controller in an attempt to remain the constant power transmission of the YN LCC. However, since there is no more room for the GD MMC station to accommodate the imbalanced power, a slight reduction will occur in the DC power through the LCC rectifier during the fault. For the sending-end YN power grid, the mechanical powers of the generators remain nearly constant during the fault. So the reduction of the power transmitted by the LCC rectifier will result in a slight increase of the frequency in the sending-end power system, as shown in Figure 10b. From the simulation results, it is seen that the whole AC/DC system quickly regains stable operation after the fault is cleared. 


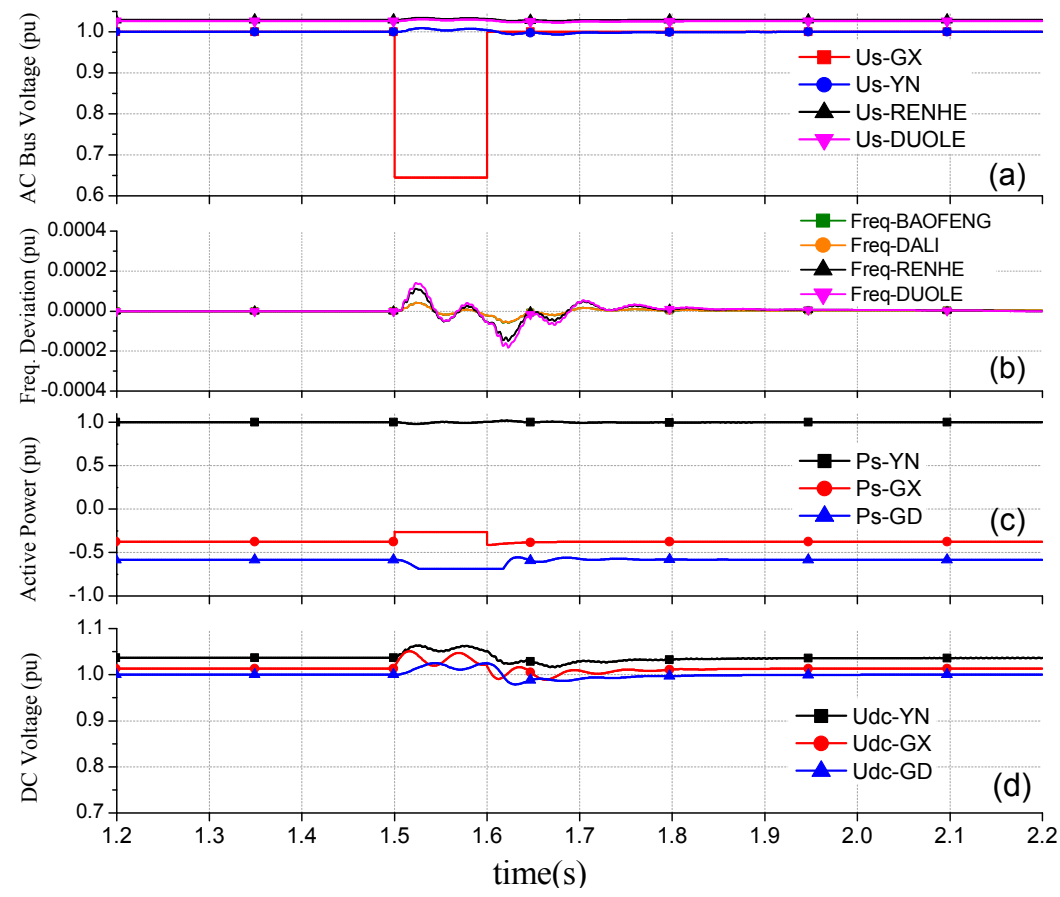

Figure 10. Dynamic performances of the hybrid multi-terminal HVDC system under GX bus fault. (a) AC bus voltage; (b) Frequency deviation; (c) Active power; (d) DC voltage.

2. AC fault at the receiving-end GD MMC station:

In this case, a three-phase short circuit fault with $0.1 \mathrm{~s}$ duration is applied at the bus of receiving-end GD MMC station, leading the bus voltage drops to 0.48 pu during the fault. The dynamic responses are shown in Figure 11.
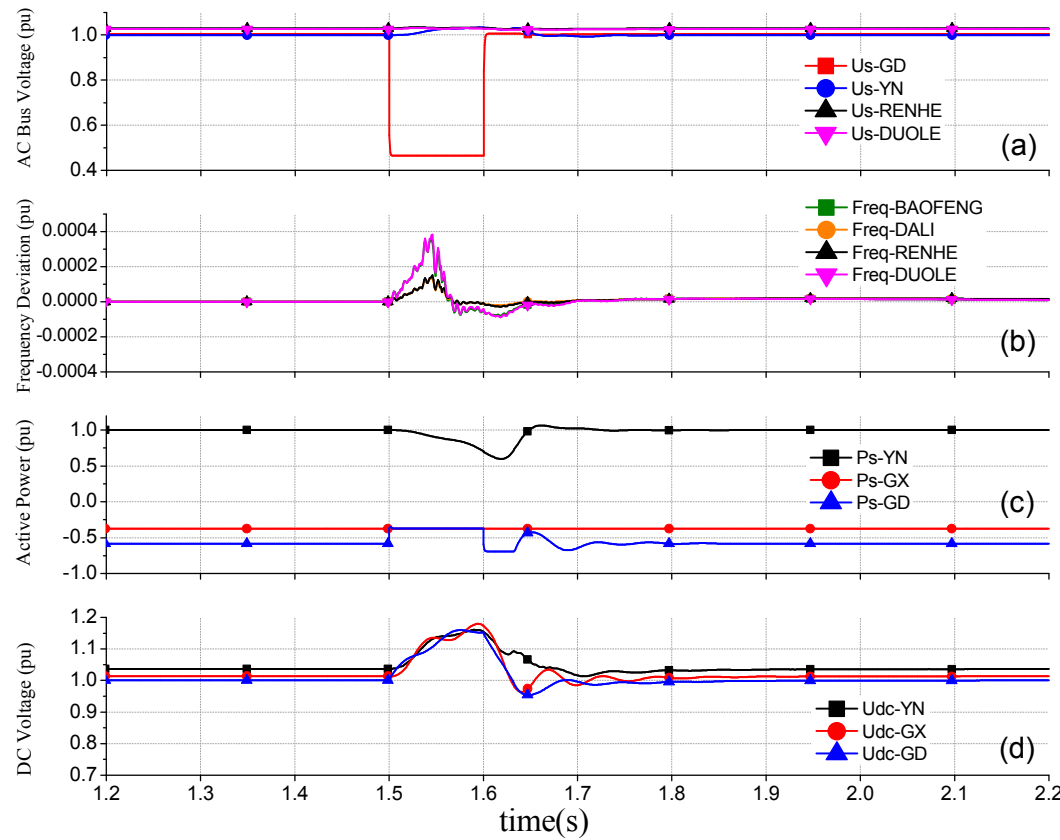

Figure 11. Dynamic performances of the hybrid multi-terminal HVDC system under GD bus fault. (a) AC bus voltage; (b) Frequency deviation; (c) Active power; (d) DC voltage. 
It is observed that during the fault at the GD converter bus, the power injected to the GD decreases, as shown in Figure 11c. Thus the power drawn from the sending-end $\mathrm{YN}$ region is more than those injected into the receiving-end GX and GD regions, leading a DC voltage surge during the transient, as shown in Figure 11d.

From Figure 11c, it can be observed that the power imbalance is mainly compensated by the LCC station during the fault. This is because the increase of the DC voltage leads to a decrease of the current reference of the constant current controller of the LCC. As a result, the DC power through the LCC rectifier is reduced during the fault. For the sending-end $\mathrm{YN}$ power grid, the mechanical powers of the generators remain nearly constant during the fault. So the reduction of the power transmitted by the LCC rectifier will result in an increase of the frequency in the sending-end power system, as shown in Figure 11b. From the simulation results, it is seen that the whole AC/DC system quickly regains stable operation after the fault is cleared.

3. AC fault at the sending-end YN LCC station:

In this case, a three-phase short circuit fault with $0.1 \mathrm{~s}$ duration is applied at the bus of sending-end YN LCC station, leading the bus voltage drops to 0.85 pu during the fault. The dynamic responses are shown in Figure 12.

It is observed that during the fault at the YN converter bus, the power transmitted by the LCC decreases, as shown in Figure 12d. Thus the power drawn from the sending-end YN region is less than those injected into the receiving-end GX and GD regions, leading a DC voltage sag during the transient, as shown in Figure 12b.
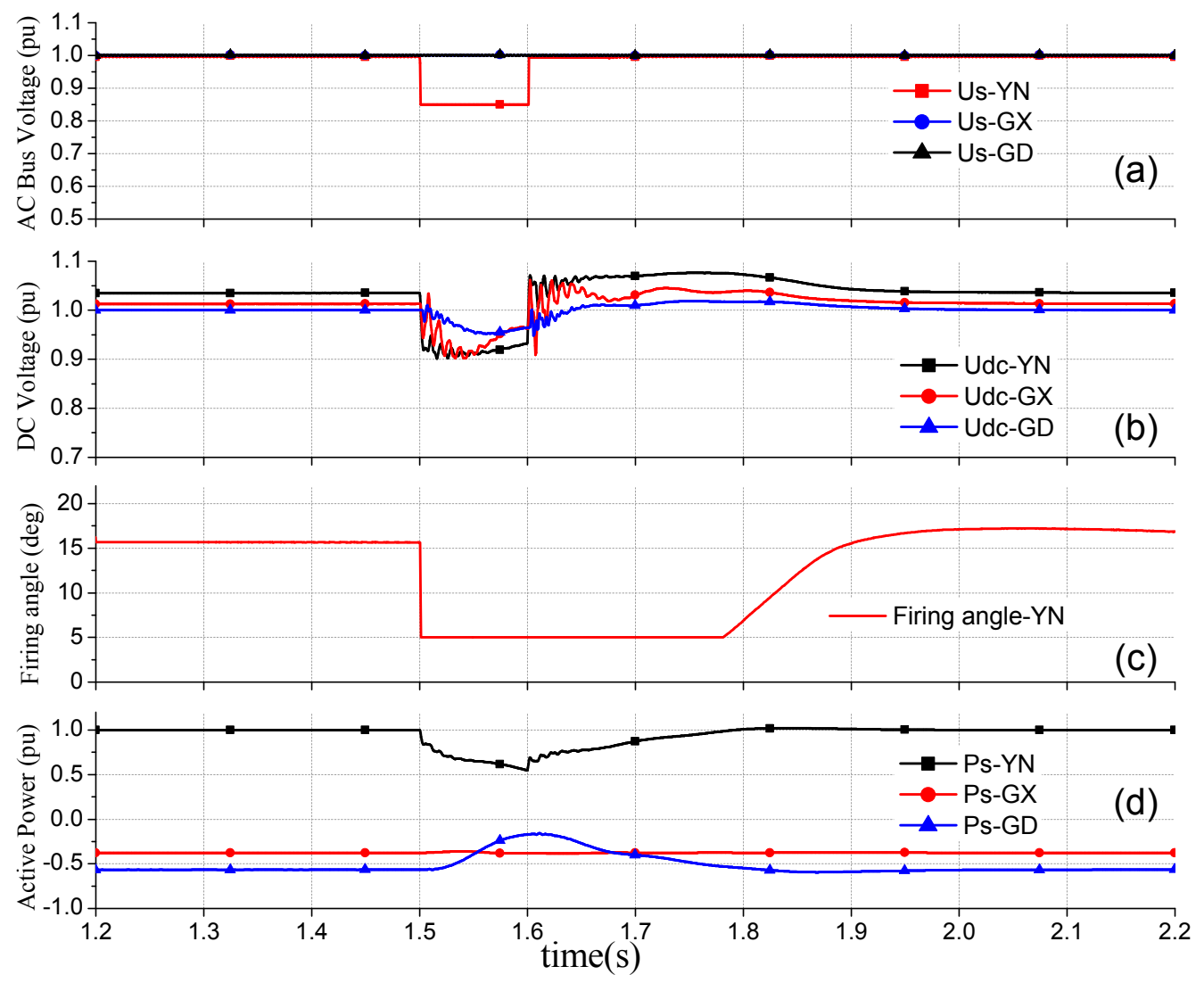

Figure 12. Dynamic performances of the hybrid multi-terminal HVDC system under YN bus fault. (a) AC bus voltage; (b) DC voltage; (c) Firing angle; (d) Active power. 
From Figure 12c, it can be observed that under the unserious fault, the LCC station is no longer in the constant current control mode, but rather in the minimum firing angle control mode with $\alpha$ fixed to $5^{\circ}$. This is because the decrease of the DC voltage leads to an increase of the current reference of the constant current controller of the LCC. From the controller structure shown in Figure 4, it is noted that the increase of the current reference eventually leads to a decrease of the firing angle $\alpha$ until it hits the lower bound limit of the controller. As long as the current reference is larger than the actual direct current of the LCC, the controller will remain in minimum firing angle control mode. After the fault is cleared, it takes nearly $200 \mathrm{~ms}$ for the actual direct current of the LCC to be pulled back to its normal level. Then, the LCC station returns to the constant current control mode. From the simulation results, it is seen that the transient stability of the whole AC/DC system is not affected after the fault is cleared.

\section{Conclusions}

This paper proposes an improved electromechanical model of LCC-MMC hybrid MTDC system for large-scale power system transient stability study. In terms of MMC modeling, it is concluded that the DC-side model of the MMC should be established as a second-order circuit, rather than the conventional first-order circuit. For the initialization of the LCC-MMC hybrid MTDC model, a sequential algorithm considering the firing angle limits of the LCC is proposed, which is particularly suitable for the power flow solution of large-scale AC/DC system. Results of the power flow show that if the firing angle limits are not taken into considering, the accuracy of the power flow solutions will be greatly affected. Steady state and dynamic simulation show that the developed LCC-MMC hybrid MTDC model is accurate enough for electromechanical transient stability studies of large-scale AC/DC system. Simulations in the Southern China Power Grid embedded with the three-terminal hybrid HVDC system show that under the three-phase short-circuit fault on the bus of different converters, the whole AC/DC system can resume stable operation after the fault is cleared. In future, the impact of different control strategies (e.g., the LCC station is responsible for DC voltage control; the MMC adopts droop control, etc.) on the transient stability of the AC/DC system will be investigated.

Author Contributions: Conceptualization, Z.X.; Methodology, Z.X. and L.X.; Validation, L.X.; Formal Analysis, L.X.; Investigation, L.X., Y.L., H.X. and Z.Z.; Writing-Review \& Editing, L.X., Y.L., H.X. and Z.Z.; Supervision, Z.X.

Funding: This research was funded by the Key Research Projects of State Grid Jiangsu Electric Power Co., Ltd. (SGJSJY00GHJS1800081).

Conflicts of Interest: The authors declare no conflict of interest.

\section{Appendix A}

The detailed parameters of models presented in Section 2.3 are given in Table A1. Besides, for the DC line, the lumped $R_{\mathrm{br}}=1.14 \Omega, L_{\mathrm{br}}=93.56 \mathrm{mH}, C_{\mathrm{br}}=0.62 \mu \mathrm{F}$.

Table A1. System Parameters of the MMC-HVDC Link.

\begin{tabular}{ccc}
\hline Item & Retifier & Inverter \\
\hline Rated L-L RMS voltage of AC system $(\mathrm{kV})$ & 220 & 220 \\
Equivalent system impedance $(\Omega)$ & $0.484+\mathrm{j} 4.84$ & $0.484+\mathrm{j} 4.84$ \\
Rated capacity of MMC $(\mathrm{MVA})$ & 400 & 400 \\
Rated DC voltage $(\mathrm{kV})$ & 400 & 400 \\
\hline Rated capacity of transformer $(\mathrm{MVA})$ & 480 & 480 \\
Nominal ratio of transformer $(\mathrm{kV})$ & $220: 210$ & $220: 210$ \\
Leakage inductance of transformer $(\mathrm{mH})$ & 35 & 35 \\
\hline Arm inductance of MMC $(\mathrm{mH})$ & 76 & 76 \\
Arm resistance of MMC $(\Omega)$ & 0.48 & 0.48 \\
Number of sub module per arm & 200 & 200 \\
Capacitance of sub module $(\mu \mathrm{F})$ & 6667 & 6667 \\
Smoothing reactor $(\mathrm{mH})$ & 100 & 100 \\
\hline Control mode & constant $P_{\mathrm{s}}+Q_{\mathrm{s}}$ & ${\text { constant } U_{\mathrm{dc}}+Q_{\mathrm{s}}}^{*} U_{\mathrm{dc}}^{*}: 400, Q_{\mathrm{s}}^{*}: 0$ \\
\hline Reference $(\mathrm{MW} / \mathrm{Mvar} / \mathrm{kV})$ & $P_{\mathrm{s}}^{*}: 400, Q_{\mathrm{s}}^{*}: 0$ & \\
\hline
\end{tabular}


The detailed parameters of models presented in Section 4.1 are given in Table A2. Besides, for the DC line from YN to GX, the lumped $R_{\mathrm{br} 1}=3.75 \Omega, L_{\mathrm{br} 1}=737.4 \mathrm{mH}, C_{\mathrm{br} 1}=12.1 \mu \mathrm{F}$; for the DC line from GX to GD, the lumped $R_{\mathrm{br} 2}=3.63 \Omega, L_{\mathrm{br} 2}=462.3 \mathrm{mH}, C_{\mathrm{br} 2}=6.5 \mu \mathrm{F}$, these parameters are calculated based on the datas provided by manufacturers.

Table A2. Monopole System Parameters of Case 1.

\begin{tabular}{cccc}
\hline Item & LCC-YN & MMC-GX & MMC-GD \\
\hline Converter rated capacity: $S_{\mathrm{N}}(\mathrm{MVA})$ & 4000 & 1500 & 2500 \\
Rated DC voltage: $U_{\mathrm{dcN}}(\mathrm{kV})$ & +800 & +800 & +800 \\
Nominal transformer ratio: $k_{\mathrm{N}}(\mathrm{kV})$ & $525: 178$ & $525: 440$ & $525: 440$ \\
Step size of transformer tap: $T_{\mathrm{tap}}$ & $1.25 \%$ & $/$ & $/$ \\
Leakage reactance: $X_{\mathrm{tr}}(\mathrm{pu})$ & 0.2 & 0.16 & 0.18 \\
Arm inductance: $L_{\mathrm{arm}}(\mathrm{mH})$ & $/$ & 81 & 49 \\
Number of sub module per arm: $N$ & $/$ & 400 & 400 \\
Capacitance of sub module: $C_{\mathrm{sm}}(\mu \mathrm{F})$ & $/$ & 12500 & 20833 \\
Smoothing reactor: $L_{\mathrm{dc}}(\mathrm{mH})$ & 100 & 100 & 75 \\
Loss ratio: $r \%)$ & 0 & 1 & 1 \\
Control mode & constant $I_{\mathrm{dc}}$ & constant $P_{\mathrm{s}}+Q_{\mathrm{s}}$ & $\mathrm{constant}_{\mathrm{dc}}+Q_{\mathrm{s}}$ \\
Reference $(\mathrm{MW} / \mathrm{Mvar} / \mathrm{kV})$ & $P_{\mathrm{dc}}{ }^{*}: 4000$ & $P^{*}: 1500, Q_{\mathrm{s}}^{*}: 0$ & $U_{\mathrm{dc}}{ }^{*}: 800, Q_{\mathrm{s}}^{*}: 0$ \\
\hline
\end{tabular}

The abbreviations used in this paper are summarized in the following table.

Table A3. Summarization of the Abbreviations.

\begin{tabular}{cc}
\hline Abbreviation & Description \\
\hline LCC & line commutated converter \\
MMC & modular multilevel converter \\
HVDC & high voltage direct current transmission \\
VSC & voltage source converter \\
MTDC & multi-terminal HVDC \\
YN & Yunnan (Province of China) \\
GX & Guangxi (Province of China) \\
GD & Guangdong (Province of China) \\
CSPG & China Southern Power Grid \\
DAEs & differential-algebraic equations \\
CV-controlled & constant DC voltage controlled \\
PSS/E & Power System Simulation for Engineering, \\
PSASP & Power System Analysis Software Package \\
PSCAD & Power Systems Computer Aided Design \\
\hline
\end{tabular}

\section{References}

1. HVDC Grid Feasibility Study. Available online: http://eepublishers.co.za/wp-content/uploads/legacy/ Energize_2013/07_TT_05_HVDC.pdf (accessed on 1 July 2018).

2. An, T.; Tang, G.; Wang, W. Research and application on multi-terminal and DC grids based on VSC-HVDC technology in China. High Volt. 2017, 2, 1-10. [CrossRef]

3. Pierri, E.; Binder, O.; Hemdan, N.G.A.; Kurrata, M. Challenges and opportunities for a European HVDC grid. Renew. Sustain. Energy Rev. 2017, 70, 427-456. [CrossRef]

4. Torres-Olguin, R.E.; Molinas, M.; Undeland, T. Offshore wind farm grid integration by VSC technology with LCC-based HVDC transmission. IEEE Trans. Sustain. Energy 2012, 3, 899-907. [CrossRef]

5. Tang, G.; Xu, Z. A LCC and MMC hybrid HVDC topology with DC line fault clearance capability. Int. J. Electr. Power Energy Syst. 2014, 62, 419-428. [CrossRef]

6. Xu, Z.; Wang, S.; Xiao, H. Hybrid high-voltage direct current topology with line commutated converter and modular multilevel converter in series connection suitable for bulk power overhead line transmission. IET Power Electron. 2016, 9, 2307-2317. [CrossRef] 
7. Jung, J.J.; Cui, S.; Lee, J.H.; Sul, S.K. A new topology of multilevel VSC converter for a hybrid HVDC transmission system. IEEE Trans. Power Electron. 2017, 32, 4199-4209. [CrossRef]

8. Lu, Y.; Li, J.; Qiu, P.; Xiao, H.; Liu, G.; Xu, Z. Comparison of DC fault handling strategies for hybrid HVDC system. In Proceedings of the 43rd Annual Conference on the IEEE Industrial Electronic Society, Beijing, China, 29 October-1 November 2017; pp. 146-151.

9. Dong, S.; Chi, Y.; Li, Y. Active voltage feedback control for hybrid multiterminal hvdc system adopting improved synchronverters. IEEE Trans. Power Deliv. 2016, 31, 445-455. [CrossRef]

10. Zeng, R.; Xu, L.; Yao, L.; Finney, S.J.; Wang, Y. Hybrid HVDC for integrating wind farms with special consideration on commutation failure. IEEE Trans. Power Deliv. 2016, 31, 789-797. [CrossRef]

11. Zhang, Z.; Xu, Z.; Xue, Y.; Tang, G. DC-Side harmonic currents calculation and DC-Loop resonance analysis for an LCC-MMC hybrid HVDC transmission system. IEEE Trans. Power Deliv. 2015, 30, 642-651. [CrossRef]

12. Lin, Y.; Xu, Z.; Xiao, L.; Zhang, Z.; Xiao, H. Analysis of coupling effect on LCC-MCC hybrid HVDC from parallel AC lines in close proximity. In Proceedings of the Sower \& Energy Society General Meeting, Denver, CO, USA, 26-30 July 2015; pp. 1-5.

13. Kotb, O.; Ghandhari, M.; Eriksson, R.; Sood, V.K. On small signal stability of an AC/DC power system with a hybrid MTDC network. Electr. Power Syst. Res. 2016, 136, 79-88. [CrossRef]

14. Guo, C.; Yin, Z.; Zhao, C.; Iravani, R. Small-signal dynamics of hybrid LCC-VSC HVDC systems. Electr. Power Energy Syst. 2018, 98, 362-372. [CrossRef]

15. Wu, X.; Hu, X.; Teng, Y.; Qian, S.; Cheng, R. Optimal integration of a hybrid solar-battery power source into smart home nanogrid with plug-in electric vehicle. J. Power Sources 2017, 363, 277-283. [CrossRef]

16. Siano, P. Demand response and smart grids-A survey. Renew Sustain. Energy Rev. 2014, 30, 461-478. [CrossRef]

17. Barnes, M.; Hertem, D.V.; Teeuwsen, S.P.; Callavik, M. HVDC systems in smart grids. Proc. IEEE 2017, 105, 2082-2098. [CrossRef]

18. Prabna, K. Power System Stability and Control; McGraw-Hill: New York, NY, USA, 1994.

19. Hahn, C.; Andreas, G.; Matthias, L. Modelling and Control Design of Hybrid-LCC and VSC based-HVDC Systems. In Proceedings of the Transmission and Distribution Conference and Exposition on the IEEE Power \& Energy Society, Dallas, TX, USA, 3-5 May 2016; pp. 1-6.

20. Zi, P.; Zhao, Z.; Chen, X.; Zhou, X.; Wan, L.; Shi, H.; An, N.; Tian, F. Electromechanical transient modeling of hybrid DC grid based on LCC and VSC converter. Proc. CSEE 2015, 35, 6265-6274. (In Chinese)

21. Lei, J.; An, T.; Du, Z.; Yuan, Z. A General Unified AC/DC Power Flow Algorithm with MTDC. IEEE Trans. Power Syst. 2017, 32, 2837-2846. [CrossRef]

22. Chai, R.; Zhang, B.; Dou, J.; Hao, Z.; Zheng, T. Unified power flow algorithm based on the nr method for hybrid AC/DC grids incorporating VSCs. IEEE Trans. Power Syst. 2016, 31, 4310-4318. [CrossRef]

23. Bandaru, T. Newton-Raphson load flow model for hybrid multi-terminal HVDC systems consisting of voltage sourced converters and line commutated converters. In Proceedings of the IEEE Students Conference on Engineering and Systems, Allahabad, India, 6-8 November 2015; pp. 1-6.

24. Beerten, J.; Cole, S.; Belmans, R. Generalized steady-state VSC mtdc model for sequential AC / DC power flow algorithms. IEEE Trans. Power Syst. 2012, 27, 821-829. [CrossRef]

25. Liang, H.; Zhao, X.; Yu, X.; Gao, Y.; Yang, J. Study of power flow algorithm of AC/DC distribution system including VSC-MTDC. Energies 2015, 8, 8391-8405. [CrossRef]

26. Dou, J.; Zhang, B.; Chai, R. A sequential power flow algorithm for AC/DC networks incorporating hybrid HVDC. In Proceedings of the Power and Energy Engineering Conference on the IEEE Power \& Energy Society, Xi'an, China, 25-28 October 2016; pp. 773-779.

27. Khan, M.O.; Jamali, S.Z.; Noh, C.H.; Gwon, G.H.; Kim, C.H. A load flow analysis for AC/DC hybrid distribution network incorporated with distributed energy resources for different grid scenarios. Energies 2018, 11, 367. [CrossRef]

28. Guide for the Development of Models for HVDC Converters in a HVDC Grid. Available online: http:/ / b4.cigre.org/Publications/Technical-Brochures/TB-604-2014-B4-57-Guide-for-the-Developmentof-Models-for-HVDC-Converters-in-a-HVDC-Grid (accessed on 13 August 2018).

29. Liu, S.; Xu, Z.; Hua, W.; Tang, G.; Xue, Y. Electromechanical transient modelling of modular multilevel converter based multi-terminal HVDC systems. IEEE Trans. Power Syst. 2014, 29, 72-83. [CrossRef] 
30. Trinh, N.T.; Zeller, M.; Wuerflinger, K.; Erlich, I. Generic model of MMC-VSC-HVDC for interaction study with AC power system. IEEE Trans. Power Syst. 2016, 31, 27-34. [CrossRef]

31. Kou, L.; Zhu, L.; Li, F. Electromechanical transient model of HVDC grids based on modular multilevel converter. In Proceedings of the Energy Internet and Energy System Integration (EI2), Beijing, China, 26-28 November 2017; pp. 1-6.

32. Saad, H.; Dennetière, S.; Mahseredjian, J.; Delarue, P.; Guillaud, X.; Peralta, J.; Nguefeu, S. Modular multilevel converter models for electromagnetic transients. IEEE Trans. Power Deliv. 2014, 29, 1481-1489. [CrossRef] 